\title{
Swan foraging shapes spatial distribution of two submerged plants, favouring the preferred prey species
}

\author{
Håkan Sandsten · Marcel Klaassen
}

Received: 1 February 2007/ Accepted: 13 February 2008/Published online: 12 March 2008

(C) The Author(s) 2008

\begin{abstract}
Compared to terrestrial environments, grazing intensity on belowground plant parts may be particularly strong in aquatic environments, which may have great effects on plant-community structure. We observed that the submerged macrophyte, Potamogeton pectinatus, which mainly reproduces with tubers, often grows at intermediate water depth and that $P$. perfoliatus, which mainly reproduces with rhizomes and turions, grows in either shallow or deep water. One mechanism behind this distributional pattern may be that swans prefer to feed on $P$. pectinatus tubers at intermediate water depths. We hypothesised that when swans feed on tubers in the sediment, $P$. perfoliatus rhizomes and turions may be damaged by the uprooting, whereas the small round tubers of $P$. pectinatus that escaped herbivory may be more tolerant to this bioturbation. In spring 2000 , we transplanted $P$. perfoliatus rhizomes into a $P$. pectinatus stand and followed growth in plots protected and unprotected, respectively, from bird foraging. Although swan foraging reduced tuber biomass in unprotected plots, leading to lower $P$. pectinatus density in spring 2001, this species grew well both in protected and unprotected plots later that summer. In contrast, swan grazing had a dramatic negative effect on $P$. perfoliatus
\end{abstract}

Communicated by Dag Olav Hessen.

\section{H. Sandsten}

Limnology, Department of Ecology, Lund University, Lund, Sweden

e-mail: hakan.sandsten@calluna.se

M. Klaassen $(\bowtie)$

Centre for Limnology, Netherlands Institute of Ecology

(NIOO-KNAW), P.O. Box 1299, 3600 BG Maarssen,

The Netherlands

e-mail: m.klaassen@nioo.knaw.nl that persisted throughout the summer of 2001, with close to no plants in the unprotected plots and high densities in the protected plots. Our results demonstrate that herbivorous waterbirds may play a crucial role in the distribution and prevalence of specific plant species. Furthermore, since their grazing benefitted their preferred food source, the interaction between swans and $P$. pectinatus may be classified as ecologically mutualistic.

Keywords Cygnus $\cdot$ Mutualism - Potamogeton . Predator-prey interactions $\cdot$ Subterranean herbivory

\section{Introduction}

Herbivores may have considerable impact on the distribution and population dynamics of plants (e.g. Maron and Crone 2006) as well as vegetation community structure (e.g. Augustine and McNaughton 1998), but non-grassland examples of such impacts are few. Similarities between aquatic and terrestrial systems and their dependence on top-down regulation are increasingly being appreciated by ecologists (Cyr and Pace 1993; Chase 2000). However, in these broad-scale inter-system comparisons, the predation of zooplankton on algae still plays a front-stage role in the representation of aquatic plant-animal interactions. The importance of vertebrate grazing on submerged macrophytes community structure remains disputed. Among the studies reported to date on interactions between aquatic herbivores and plants, few have considered the possibility of herbivory mediating competition between plants (but see Lauridsen et al. 1993; Van Donk and Otte 1996; Santamaría 2002; LaMontagne et al. 2003), and none have experimentally shown that this can lead to a specific herbivore-induced vegetation distribution and composition. 
Considering that the impact of herbivory on community structure in terrestrial systems increases with grazing intensity (Augustine and McNaughton 1998), the study of some aquatic plant-animal interactions with sometimes extremely high grazing pressures on both above- and belowground parts may prove rewarding.

Potamogeton pectinatus and $P$. perfoliatus are two species of aquatic macrophytes typical of eutrophic lakes, often co-occurring, with a more or less cosmopolitan distribution. They hibernate mainly vegetatively with rhizomes and turions ( $P$. perfoliatus) or specialised tubers (P. pectinatus) in the sediment (Fig. 1). Many species of waterbirds rely on the leaves and seeds of these two species of water plants (Cramp and Simmons 1986). Among waterbird foragers, swans form a special group of consumers that are also capable of uprooting and consuming the belowground parts of $P$. pectinatus and $P$. perfoliatus. In particular, Bewick's (Cygnus columbianus bewickii) and whooper swans (C. cygnus) are highly dependent on the nutrient-rich tubers of $P$. pectinatus (Nolet and Drent 1998; Nolet et al. 2001, 2002; Beekman et al. 2002).

The spatial distributions and segregation of $P$. pectinatus and $P$. perfoliatus have been studied extensively. Typically, $P$. pectinatus is found in shallower waters than $P$. perfoliatus. Lehmann et al. (1997) argued that the higher tolerance of $P$. pectinatus to wave exposure in shallow water and the higher tolerance of $P$. perfoliatus to light attenuation in deep water could be a major causal factor of this distribution of the two species. Scheffer et al. (1992) was able to explain about $50 \%$ of the variation in the distribution of both species by considering water depth, transparency, spring water temperature and exposure to waves for $P$. pectinatus and water depth and transparency for $P$. perfoliatus. During extensive studies on the distribution of aquatic vegetations and swan foraging in two of our major research sites where $P$. pectinatus and

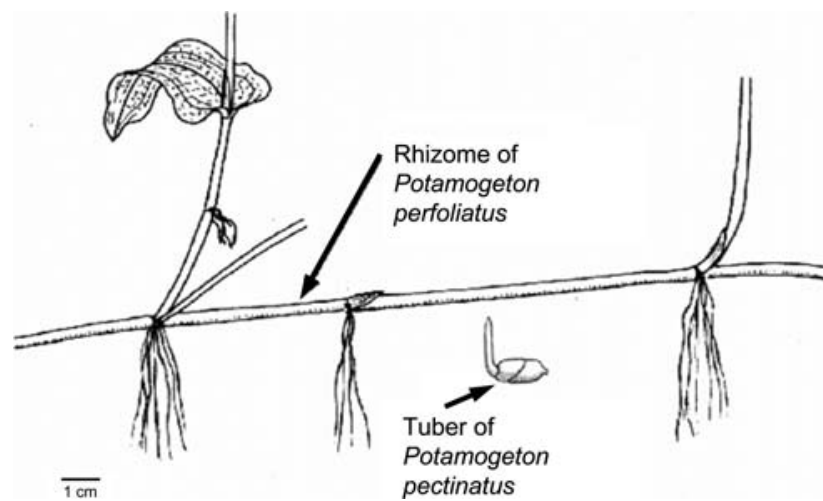

Fig. 1 Vegetative reproductive organs of Potamogeton perfoliatus and $P$. pectinatus. The tubers of $P$. pectinatus may considerably vary in size between approximately 2 and $16 \mathrm{~mm}$. The depicted tuber is $15 \mathrm{~mm}$ long
P. perfoliatus co-occur (Pechora Delta, in Arctic Russia, and Lake Ringsjön, in southern Sweden), we noticed that $P$. perfoliatus occurred not only in deep water but also in very shallow water seldom visited by tuber-feeding swans. We thus hypothesised that swan foraging, which is limited to areas of intermediate depth (Beekman et al. 1991; Nolet et al. 2001; Sandsten 2002), at least partly determines the distribution of $P$. perfoliatus.

In order to investigate how swan feeding on tubers of $P$. pectinatus affects the growth of $P$. perfoliatus, we monitored vegetation and swan foraging and performed a transplant experiment in Eastern Lake Ringsjön, Sweden. Potamogeton perfoliatus was planted in a $P$. pectinatus stand after which the development of both species was followed in the presence and absence of swan grazing.

\section{Methods}

Eastern Lake Ringsjön $\left(55^{\circ} 52^{\prime} \mathrm{N}, 13^{\circ} 32^{\prime} \mathrm{E}\right)$ is a eutrophic, $20.5-\mathrm{km}^{2}$ large lake with a maximum and mean depth of 16.4 and $6.1 \mathrm{~m}$, respectively. The experiment was set up in Fulltofta Bay $\left(0.7 \mathrm{~km}^{2},<1 \mathrm{~m}\right.$ deep; Fig. 2), which is a wind exposed, shallow and sandy part of Eastern Lake Ringsjön, with an aquatic vegetation that nearly exclusively consists of $P$. pectinatus and $P$. perfoliatus. Every year from September to November, Fulltofta Bay hosts

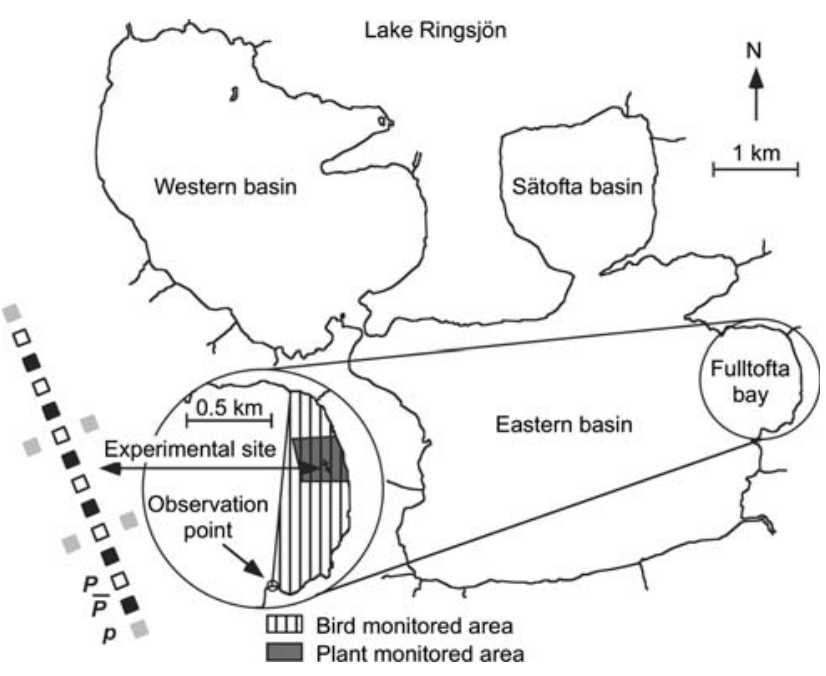

Fig. 2 Map of Lake Ringsjön with an enlargement of Fulltofta Bay and an overview of the bird-monitored and plant-monitored areas as well as the plant-experimental site. Enlargement of the plantexperimental site shows the six replicates of three treatments, with gray squares representing plots where no $P$. perfoliatus was planted and no protection from waterbirds was provided until 18 December 2000 at which time all treatments were covered with metal nets on the bottom (treatment $p$ ). Black squares represent plots with planted $P$. perfoliatus that were continuously protected by nets (treatment $\bar{P}$ ). White squares represent plots with planted $P$. perfoliatus that were unprotected from 8 August to 18 December 2000 (treatment $P$ ) 
large numbers of migrating waterbirds (up to 1600 individuals, Sandsten 2002). Many of these migrating waterbird species, notably swans (whooper swans $C$. cygnus, Bewick's swans C. columbianus bewickii, and mute swans $C$. olor), feed on tubers of $P$. pectinatus and rhizomes and turions of $P$. perfoliatus by digging in the sandy sediment (e.g. Cramp and Simmons 1986; Nolet and Drent 1998; Sandsten 2002). Coot (Fulica atra) and various species of ducks (mallard Anas platyrhynchos, pintail Anas acuta, wigeon Anas penelope, goldeneye Bucephala clangula, tufted duck Aythya fuligula, pochard Aythya ferina) may also forage on tubers, but nearly always in association with swans since they are unable to dig up the tubers from the sediment by themselves (e.g. Cramp and Simmons 1986; Sandsten 2002). Geese (mainly Anser anser) roost frequently in the area, but they very seldom feed on tubers (Cramp and Simmons 1986; personal observations, H. Sandsten).

To quantify our impression that $P$. perfoliatus occurs only in very shallow and relatively deep parts of Fulltofta Bay, we mapped the occurrence of $P$. pectinatus and $P$. perfoliatus in relation to water depth in Fulltofta Bay on 10 August 2000 (Fig. 2). Vegetation and water depths were examined on 173 points regularly spaced (at 20$30 \mathrm{~m}$ distance from point to point) in an area $\left(0.12 \mathrm{~km}^{2}\right)$ running from the shore to a depth of $1.2 \mathrm{~m}$. The geographical position of each sampling point was measured with a GPS (Garmin Personal Navigator 12 XL). On each of the points we investigated plant occurrence three times by throwing a $50 \times 50-\mathrm{cm}$ metal frame into the water and diving down to look for plants. For $P$. pectinatus, a cover index was used, where 0 was no ramets $\mathrm{m}^{-2}$, 1 was 120 ramets $\mathrm{m}^{-2}, 2$ was $21-80$ ramets $\mathrm{m}^{-2}$ and 3 was $>80$ ramets $\mathrm{m}^{-2}$. We counted all shoots emerging from the sediment surface as ramets. Potamogeton perfoliatus shoots were less frequent than $P$. pectinatus shoots and seldom found in the frames-possibly because of less favourable growing conditions but at least in part because of its morphology and growth strategy. We therefore used data on absence/presence in the proximity (within a radius of $10 \mathrm{~m}$ ) of the sampling point. The data were entered into a geographic information system, GIS (Surfer 6.04) and interpolated over the entire monitored surface using intermediate distance interpolation.

Swans were counted over an area of $0.54 \mathrm{~km}^{2}$ from an observation point (Fig. 2) south of Fulltofta Bay on 5, 17 and 30 August, 10 and 23 September, 5, 18 and 28 October and 9 November 1999.

Swans foraging on tubers tread water to create a water current that flushes the sediment and uncovers tubers and rhizomes, resulting in the appearance of pits and piles of sediment on the bottom at the sites where foraging activity has taken place. Wave action will ultimately level the sediment again (Sandsten 2002). Depth heterogeneity was used as an indirect measure of waterbird foraging on tubers in the sediment. In order to investigate the timing of swan foraging in relation to water depth we measured depth heterogeneity along five fixed transects running parallel to the shore within the plant-monitored area. The transects were aimed to be at equidistant intervals parallel to the shore, but in fact they were located at a distance of 110 , $180,260,340$ and $400 \mathrm{~m}$ from the shore (mean depths were 37, 45, 60, 75 and $90 \mathrm{~cm}$ on 5 August 1999). Depth heterogeneity was obtained by calculating the SD from $5 \times 10$ measurements of water depth along each transect. Within every second metre along the 11-m-long transect ten water depths were measured at a distance of $10 \mathrm{~cm}$, resulting in five SD from each transect. These five SD were entered as replicates from each transect in the statistical analysis and were also the basis for the graphical presentation of "mean standard deviation". Measurements were conducted prior to and during the main swan grazing period on 5, 17 and 30 August, 10 and 23 September, 5 and 18 October and 1 and 12 November 1999. Depth heterogeneity in relation to time of measurement and mean water depth was statistically analysed using repeated measures ANOVA (Statistica ver. 5.1; StatSoft, Tulsa, OK). Normal distribution of residuals was checked with a probability plot, and heteroscedasticity of variances was checked for with Levene's test. If the variances were not homogenous or the plots of residuals were not linear, the data were transformed to meet the assumptions of ANOVA.

The transplant experiment consisted of three separate treatments with six replicate plots $(1.4 \times 1.4 \mathrm{~m})$, all situated in an established (at least for 5 years) stand of $P$. pectinatus in Fulltofta Bay (Fig. 2). The experiment ran from 31 May 2000 until 15 August 2001. One treatment, $\bar{P}$, consisted of continuously protected plots where rhizomes with ramets of $P$. perfoliatus had been planted among the $P$. pectinatus plants. The second treatment, $P$, consisted of plots where ramets of $P$. perfoliatus had also been planted among the $P$. pectinatus plants, but where swans were allowed to graze during the autumn migratory period ( 8 August until 18 December 2000). The last treatment, $p$, consisted of $P$. pectinatus plots without $P$. perfoliatus where swans were allowed to graze permanently. This last treatment was designed as a control treatment to check for any effects of the planting of $P$. perfoliatus on $P$. pectinatus. Ramets of $P$. perfoliatus were collected in the eastern part of the nearby Lake Krankesjön $\left(55^{\circ} 42^{\prime} \mathrm{N}, 13^{\circ} 28^{\prime} \mathrm{E}\right)$ by scuba diving on 30 May 2000 just after onset of sprouting. The collected ramets with roots and intact meristems and varying in size from 30 to $70 \mathrm{~cm}$ were stored in plastic bags at $5^{\circ} \mathrm{C}$ overnight. On the following day, 22 ramets (density $11 \mathrm{~m}^{-2}$ ) with roots and intact meristems were planted in each of the $\bar{P}$ and $P$ plots. The randomly selected 
ramets were distributed evenly over the plots and planted at a depth of $10 \mathrm{~cm}$. The plots were subsequently protected with a $1.6-\mathrm{m}$ high plastic net (mesh size $25 \times 32 \mathrm{~mm}$ ). The $p$ plots were not protected since summer grazing on aboveand belowground biomass of $P$. pectinatus is considered negligible (Santamaría 2002).

In all 18 plots, the above- and belowground biomass of the vegetation was surveyed by scuba diving and core sampling prior to the migratory and main grazing period of the swans, on 8 August 2000. After the main swan-grazing period (verified by counts on 18 July, 8 and 18 August, 8 September, 4 and 24 October and 2 November 2000, yielding 22, 18, 34, 10, 10, 10 and 10 swans $\mathrm{km}^{-2}$, respectively), the belowground biomass was again surveyed by core sampling on 18 December 2000. Finally, the effect of swan grazing on the aboveground plant biomass during the autumn of 2000 was again assessed by scuba diving on 6 June and 15 August 2001 the following growth season. Aboveground biomass was evaluated by counting all ramets emerging from the sediment in two perpendicular transects (5 cm wide, $2.0 \mathrm{~m}$ long) running diagonally across each plot. Belowground biomass was sampled using four sediment core samples (diameter $11 \mathrm{~cm}$, length $30 \mathrm{~cm}$ ) in each plot. Roots, rhizomes and tubers of $P$. pectinatus and roots and rhizomes of $P$. perfoliatus were dried at $105^{\circ} \mathrm{C}$ for $24 \mathrm{~h}$ before dry weight (DW, g) measurements were taken. In December, we wanted to retain most of the $P$. pectinatus tubers for other purposes. Consequently, we first measured the fresh weight (FW, g) of each collected tuber and then assessed the DW on a subsample of randomly selected tubers. The regression of these DW estimates on FW was used to estimate total tuber $\mathrm{DW}$ of the whole sample $(\mathrm{DW}=0.2953 \mathrm{FW}, P<0.0001$, $R^{2}=0.958, n=33$ ).

Lake Ringsjön is usually covered with ice during the winter, which poses a potential threat to the fences around the plots. Therefore, on 18 December 2000, when the majority of birds had left the bay, the fences of treatment $\bar{P}$ were removed. Subsequently all plots, of treatments $\bar{P}, P$ and $p$, were covered with metal nets (mesh width $10 \times 10 \mathrm{~cm})$ to protect them from belowground winter grazing by swans during occasional periods when the lake was not ice-covered. These bottom-covering nets remained in place throughout the experiment, and counting of ramets in 2001 was carried out without removing the nets.

The experimental data were analysed with analysis of variance, ANOVA, in STATISTICA ver. 5.1. Heteroscedasticity and residuals were examined, and transformations were carried out using the same methods as for the depth heterogeneity data. Tukey's honestly significant difference (HSD) was used to test all pairwise comparisons among means when the overall treatment effect in the ANOVA was (near) significance.

\section{Results}

Vegetation and water depth mapping

The shallowest $(<20 \mathrm{~cm})$ and deepest $(>95 \mathrm{~cm})$ parts of Fulltofta Bay were void of submerged macrophytes (Fig. 3). Potamogeton pectinatus grew at depths varying from 20 to $95 \mathrm{~cm}$, with the highest ramet densities at intermediate water depths. In contrast, $P$. perfoliatus was found at relatively few points and mainly in deep water $(>70 \mathrm{~cm})$. Some $P$. perfoliatus was also found in shallow water $(20-30 \mathrm{~cm})$ but except for one finding at a depth of $46 \mathrm{~cm}$, no $P$. perfoliatus was found at intermediate water depths $(30-70 \mathrm{~cm})$.

\section{Swans}

Figure 4 (upper panel) shows swan densities in Fulltofta Bay during the autumn of 1999; swan grazing followed a similar temporal pattern in 2000 (Sandsten 2002). Depth heterogeneity largely coincided with swan densities and increased with time, indicating that swan grazing on $P$. pectinatus tubers increased from August to early November (Fig. 4, lower panel). Depth heterogeneity was significantly affected by time and the interaction between water depth and time $\left[F_{8,160}=14.38 P<0.001, F_{32,160}=3.65\right.$ $P<0.001, F_{4,20}=1.80 P=0.168$; respectively; data was

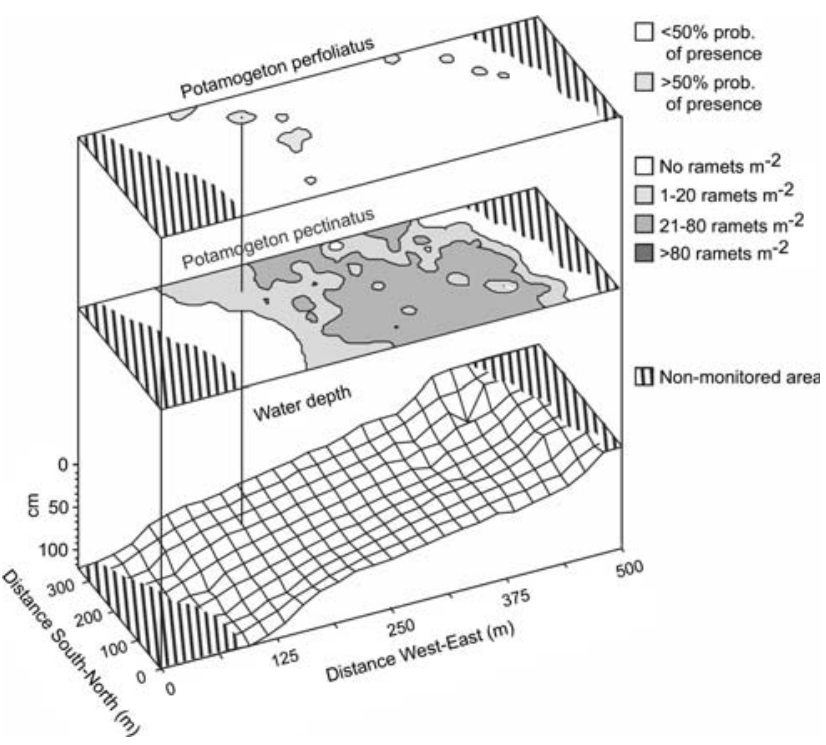

Fig. 3 Maps on vegetation and water depth in Fulltofta Bay, Lake Ringsjön. The vertical line shows the same point in the three maps. The upper map shows the distribution of $P$. perfoliatus on deep and shallow water. Grey represents areas where the probability of encountering $P$. perfoliatus on the sampling points was larger than $50 \%$. The middle map shows the distribution and abundance of $P$. pectinatus. The lower map is a three-dimensional presentation of water depths in the monitored area 

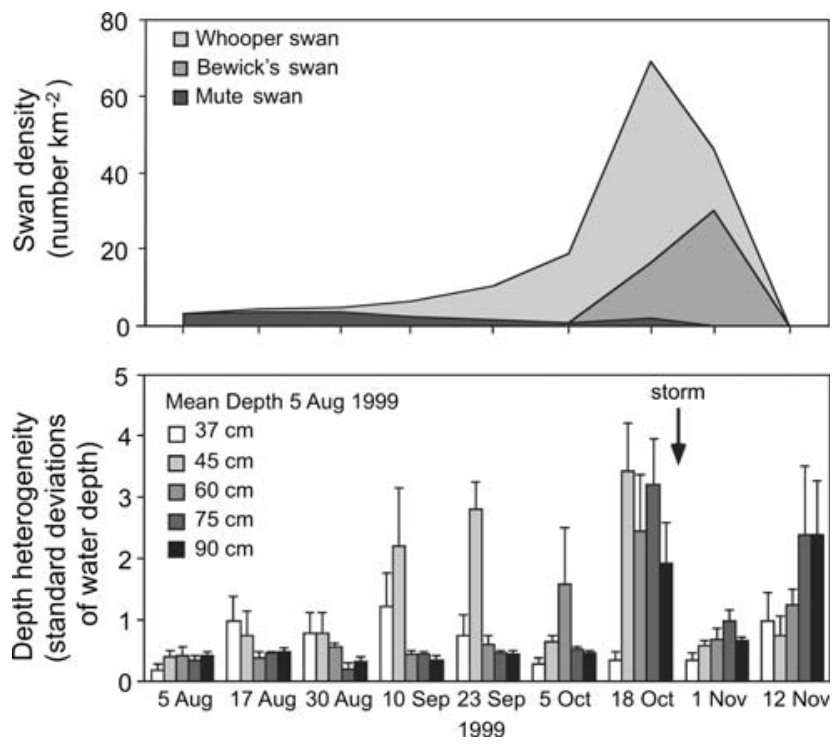

Fig. 4 The upper panel shows swan densities in Fulltofta Bay (area $0.54 \mathrm{~km}^{2}$ ) over the period August-November 1999. Swans include the whooper swan (Cygnus cygnus), Bewick's swan (C. columbianus bewickii) and mute swan $(C$. olor $)$ The lower panel shows water depth heterogeneity measured as 5 SD of water depth at five locations with different water depths. The columns show mean + standard error of these SD. Depth heterogeneity is used as an indirect measure of swan foraging on tubers in the sediment

$\ln (Y+0.1)$ transformed]. The interaction between time and water depth indicates that over time the swans' main foraging depth changed. As shown in Fig. 4, birds started foraging on macrophytes at shallow depths (37 and $45 \mathrm{~cm}$ ) in August, shifting to deeper areas $(60,75$ and $90 \mathrm{~cm})$ in October and November. During the last days of October, stormy weather events evened out the sediment, resulting in little depth heterogeneity being recorded on 1 November.

\section{Transplant experiment}

During the summer following planting, $P$. perfoliatus established well in the $\bar{P}$ and $P$ plots, as indicated by the August 2000 sampling (Fig. 5) prior to the peak swangrazing period (compare Fig. 4). A comparison of the $\bar{P}$ and $P$ treatments revealed that neither belowground biomass nor ramet density of $P$. perfoliatus differed significantly at the start of the experiment (Table 1; Fig. 5). As expected, no $P$. perfoliatus was found in the $p$ plots where no $P$. perfoliatus had been planted.

The August sampling also showed a healthy stand of $P$. pectinatus in all plots before the peak swan-grazing period. Although there seemed to be a tendency for $P$. pectinatus to perform worse in the presence of $P$. perfoliatus, no significant differences in belowground DW, ramet density or $P$. pectinatus tuber density were detected between the treatments (Table 1; Fig. 5).
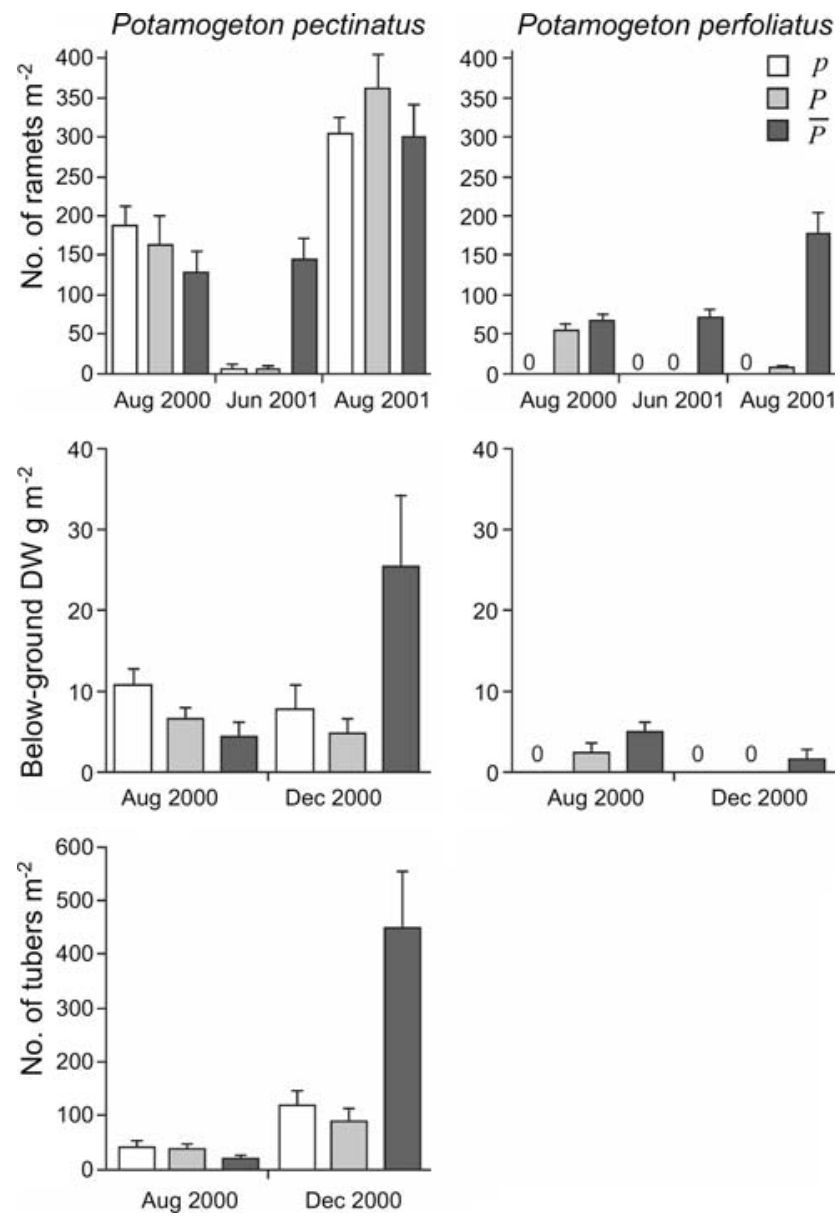

Fig. 5 Above- and belowground biomass (means and standard errors) of $P$. pectinatus and $P$. perfoliatus in the transplant experiment during various times of the year in 2000 and 2001. $\bar{P}$, six plots where $P$. perfoliatus was planted in May 2000 and where above- and belowground biomass was protected against waterbird herbivory until December 2000, $P$ six plots where $P$. perfoliatus was planted in May 2000 and above- and belowground biomass was protected against waterbird herbivory until August 2000, $p$ six "unplanted" plots without protection against herbivores until December 2000. All 18 plots were protected from waterbirds after December 2000 with metal nets covering the bottom

In December, when the majority of swans had left the lake, belowground DW was again estimated (Fig. 5). Potamogeton perfoliatus was found in three of the $\bar{P}$ and none of the other plots. Although this result suggested a negative impact of swan grazing on $P$. perfoliatus, it did not allow for any meaningful statistical analysis. In December, $P$. pectinatus belowground biomass and tuber density were higher in the $\bar{P}$ plots than in the $P$ plots $\left[F_{1,10}=7.7\right.$, $P<0.05$ after $\ln (Y+1)$ transformation, and $F_{1,10}=12$, $P<0.001$ after square $\operatorname{root}(Y+1)$ transformation, respectively], revealing the effect of tuber consumption by swans.

Ramet densities in the plots were counted in June 2001. There were significant treatment effects both on 
Table 1 ANOVA table for above- and belowground data of Potamogeton perfoliatus and $P$. pectinatus sampled in the three treatments on 8 August 2000 before the peak of waterbird herbivory

\begin{tabular}{|c|c|c|c|}
\hline Source of variation & Potamogeton sp. & $F_{d f}$ & $P$ \\
\hline \multirow[t]{3}{*}{ Ramets (number $\mathrm{m}^{-2}$ ) } & P. pectinatus ${ }^{\mathrm{a}}$ & $0.62_{1,10}$ & NS \\
\hline & P. perfoliatus ${ }^{\mathrm{a}}$ & $1.6_{1,10}$ & NS \\
\hline & P. pectinatus ${ }^{\mathrm{b}}$ & $1.0_{2,15}$ & NS \\
\hline \multirow[t]{3}{*}{ Below-ground DW $\left(\mathrm{g} \mathrm{m}^{-2}\right)$} & P. pectinatus ${ }^{\mathrm{a}}$ & $0.86_{1,10}$ & NS \\
\hline & P. perfoliatus ${ }^{\mathrm{a}}$ & $2.2_{1,10}$ & NS \\
\hline & P. pectinatus ${ }^{\mathrm{b}}$ & $3.3_{2,15}$ & NS $(0.065)^{*}$ \\
\hline \multirow[t]{2}{*}{ Tubers (number $\mathrm{m}^{-2}$ ) } & P. pectinatus ${ }^{\mathrm{a}}$ & $3.0_{1,10}$ & NS \\
\hline & $P$. pectinatus ${ }^{\mathrm{b}}$ & $1.7_{2,15}$ & NS \\
\hline
\end{tabular}

* Tukey's HSD multiple comparison between treatments resulted in a near significant effect $(P=0.058)$ for the comparison between $\bar{P}$ and $p$; NS, not significant

${ }^{\text {a }}$ Plots without planted $P$. perfoliatus excluded

${ }^{b}$ All plots included

$P$. pectinatus and $P$. perfoliatus, and both species were present at higher densities in the $\bar{P}$ plots than in the $P$ plots (Fig. 5; Table 2). In August 2001 there was still a difference in $P$. perfoliatus ramet density but not in $P$. pectinatus (Fig. 5; Table 2).

\section{Discussion}

Our vegetation mapping study supports our earlier impression that the distribution of $P$. perfoliatus is limited to those areas where the pressure of swan grazing is low. It also shows that $P$. pectinatus grows at intermediate water depths, while $P$. perfoliatus is found mainly in deep water and occasionally at shallow depths. This is consistent with reports in the literature that $P$. perfoliatus mainly grows deeper than $P$. pectinatus (Scheffer et al. 1992; Lehmann et al. 1997), although we found no other report on $P$. perfoliatus growing in very shallow water.

Depth heterogeneity substantiated our impressions of the spatial variation in foraging activity of the swans in Fulltofta Bay. Swans showed a tendency to forage at intermediate depths that are largely void of $P$. perfoliatus.

Table 2 ANOVA table on $P$. pectinatus and $P$. perfoliatus ramet density in $P$ and $\bar{P}$ plots on 6 June and 15 August 2001

\begin{tabular}{llll}
\hline Source of variation & Potamogeton sp. & $F_{d f}$ & $P$ \\
\hline Ramets $\left(n \mathrm{~m}^{-2}\right)$ in June & $P$. pectinatus & $43_{1,10}$ & $* * *$ \\
Ramets $\left(n \mathrm{~m}^{-2}\right)$ in June & $P$. perfoliatus & $565_{1,10}$ & $* * *$ \\
Ramets $\left(n \mathrm{~m}^{-2}\right)$ in August & $P$. pectinatus & $1.1_{1,10}$ & NS \\
Ramets $\left(n \mathrm{~m}^{-2}\right)$ in August & $P$. perfoliatus & $45_{1,10}$ & $* * *$ \\
\hline
\end{tabular}

$* * * P<0.001 ; \mathrm{NS}$, not significant

All data is $\ln (Y+1)$ transformed
They started to forage in relatively shallow water and moved to deeper parts, where foraging is more expensive (Nolet et al. 2001), later in the season. A similar phenomenon was observed in Bewick's Swans foraging on $P$. pectinatus in the Russian White Sea (Nolet and Drent 1998). This shift into deeper water over time may not only have been a consequence of depletion-it may also have been related to a decrease in the water table by $0.2 \mathrm{~m}$ from August to early November (Swedish Meteorological and Hydrological Institute, unpublished data). When the spatial variation in foraging activity was considered over the whole season, there was a tendency for intermediate water levels to be used more frequently than the shallow and deep parts of the bay. This result is in accordance with those from an experiment on tuber depletion at different water depths in Fulltofta Bay (Sandsten 2002) and with previous observations on $P$. pectinatus foraging swans elsewhere (Beekman et al. 1991; Nolet et al. 2001). The observed tendency of swans to preferentially forage at intermediate depths becomes even more striking when we study the depth heterogeneity in Fulltofta Bay during the month of October 1999, when swan numbers were peaking.

The results of the transplant experiment showed that subterranean swan grazing had a dramatic negative effect on $P$. perfoliatus and, consequently, on the spatial depthrelated distribution of $P$. pectinatus and $P$. perfoliatus in Fulltofta Bay and possibly elsewhere. When faced with increased subterranean herbivory, $P$. pectinatus seems to increase the depth at which its tubers are buried-likely as a defence mechanism to reduce tuber loss (Klaassen and Nolet 2007; Santamaría and Rodríguez-Gironés 2002). However, during the August-December 2000 period, $P$. pectinatus winter biomass was considerably reduced as a result of swan foraging. Both belowground tuber biomass and tuber numbers were negatively affected. At the same time, swan foraging also had a marked negative effect on the occurrence of $P$. perfoliatus in the following year. Potamogeton perfoliatus had virtually disappeared from the unprotected sites where waterbirds had free access: in December, directly after herbivory, no belowground remnants of $P$. perfoliatus were detected; in June and August of the following year, the aboveground presence of $P$. perfoliatus was marginal in the unprotected plots, which contrasted sharply with the situation in the plots that had been continuously protected from subterranean herbivory by swans. Although not as dramatic as in P. perfoliatus, tuber herbivory by swans also had an effect on the aboveground biomass of $P$. pectinatus in the spring, but differences in aboveground biomass between protected and unprotected plots were no longer detectable by August 2001. The small number of tubers remaining in $P$ was probably sufficient to produce a large number of tubers during the following autumn. This result is consistent with 
observations by LaMontagne et al. (2003) and the model of Jonzén et al. (2002), which suggest that tuber herbivory in winter leads to a lower density of ramets the following spring, but that compensation (or even overcompensation; compare Nolet 2004) of tuber production may occur the following autumn.

In Sweden, the investments of $P$. perfoliatus and $P$. pectinatus in vegetative reproduction are large. It is highly likely that the difference in their wintering strategy determines their susceptibility to subterranean foraging by swans and, consequently, their prevalence in sites regularly frequented by digging swans. The small, round and relatively robust tubers of $P$. pectinatus are a highly preferred food source by foraging swans (e.g. Cramp and Simmons 1986; Sandsten 2002; Nolet and Drent 1998). However, if missed and not eaten, they are very likely to survive the digging and uprooting activity of the swans. In contrast, the rhizomes and turions of $P$. perfoliatus are long, interconnected and relatively fragile. Compared to the solitary tubers of $P$. pectinatus, they are easily detected and, if not eaten, fragmented by the digging and uprooting of swans.

The experiment reported here was mainly designed to study competition between $P$. pectinatus and $P$. perfoliatus under autumnal swan grazing. However, during the early experimental phase, which was without grazing until August 2000, no effect of $P$. perfoliatus on $P$. pectinatus growth was observed. Nevertheless, it is rather conceivable that both species compete for nutrients and light and that the removal of $P$. perfoliatus by swans will ultimately be of benefit to $P$. pectinatus. Therefore, the swans ultimately increase the profitability of the vegetation to themselves by promoting the nutrient-rich tuber-producing $P$. pectinatus. Although subterranean feeding in $P$. pectinatus stands may also favour the establishment of new macrophyte species (LaMontagne et al. 2003), the current findings suggest that tuber-feeding herbivores may actually stimulate the development of $P$. pectinatus by mediating competition with other macrophyte species, notably $P$. perfoliatus. This outcome implies a potentially mutualistic relationship, at least in an ecological sense (sensu Järemo et al. 1999), between a predator (swan) and its prey ( $P$. pectinatus). Following Järemo et al.'s (1999) classification of mutualistic plant-herbivore interactions, the current relationship may represent a "plant-herbivore antagonism", where $P$. pectinatus has adapted itself better than competing plants to subterranean herbivory (by producing specialised clonal propagules and hiding; Klaassen and Nolet 2007) thus obtaining a relative fitness advantage over less welladapted species such as $P$. perfoliatus. However, since overcompensation to subterranean grazing may occur (Santamaría and Rodríguez-Gironés 2002; Nolet 2004), the relationship between $P$. pectinatus and swans may also be considered as an "evolution of overcompensation relationship", in which $P$. pectinatus has an absolute fitness advantage to grazing, whereas its competitors have not.

Our data support the view that waterbirds may play a crucial role in the prevalence of certain plant species with potential consequences for the functioning of the system as a whole (e.g. Engelhardt and Ritchie 2001). Reviewing the (terrestrially-skewed) literature, Augustine and McNaughton (1998) concluded that the impact on vegetation communities tends to increase with grazing intensity. In aquatic systems, belowground grazing may be facilitated by the generally softer and easily penetrable sediments, notably if grazers make use of water jets to uncover the vegetative plant parts. Grazing intensity may thus reach very high levels in these systems, resulting in very rapid alterations in vegetation composition that are uncommon in terrestrial systems.

Acknowledgments Prof. Petter Pilesjö is thanked for help with the geographic information system. Jessica D'Este and Per Sandsten are acknowledged for their indispensable help during the fieldwork. Anders Hargeby and Ola Marklund not only helped in the field, but also gave valuable comments on a previous version of this paper. Bart Nolet and two anonymous reviewers are also thanked for valuable comments on the manuscript. This is publication 4248 of the Netherlands Institute of Ecology (NIOO-KNAW).

Open Access This article is distributed under the terms of the Creative Commons Attribution Noncommercial License which permits any noncommercial use, distribution, and reproduction in any medium, provided the original author(s) and source are credited.

\section{References}

Augustine DJ, McNaughton SJ (1998) Ungulate effects on the functional species composition of plant communities: herbivore selectivity and plant tolerance. J Wildl Manage 62:1165-1183

Beekman JH, van Eerden MR, Dirksen S (1991) Bewick's swan Cygnus columbianus bewickii utilising the changing resource of Potamogeton pectinatus during autumn in the Netherlands. In: Sears J, Bacon PJ (eds) Wildfowl Supplement no. 1, 3rd IWRB Int Swan Symp. Oxford, pp 238-248

Beekman JH, Nolet BA, Klaassen M (2002) Skipping swans: differential use of migratory stopover sites in spring and autumn in relation to fuelling rates. Ardea 90:437-460

Chase JM (2000) Are there real differences among aquatic and terrestrial food webs? Trends Ecol Evol 15:408-412

Cramp S, Simmons KEL (eds) (1986) Handbook of the birds of Europe and North Africa. The birds of the western Palearctic. Oxford University Press, Oxford

Cyr H, Pace ML (1993) Magnitude and pattern of herbivory in aquatic and terrestrial ecosystems. Nature 361:148-150

Engelhardt KAM, Ritchie ME (2001) Effects of macrophyte species richness on wetland ecosystem functioning and services. Nature 411:687-689

Järemo J, Tuomi J, Nilsson P, Lennartsson T (1999) Plant adaptations to herbivory: mutualistic versus antagonistic coevolution. Oikos 84:313-320 
Jonzén N, Nolet BA, Santamaría L, Svensson MGE (2002) Seasonal herbivory and mortality compensation in a swan-pondweed system. Ecol Model 147:209-219

Klaassen M, Nolet BA (2007) The role of herbivorous water birds in aquatic systems through interactions with aquatic macrophytes, with special reference to the Bewick's swan-fennel fondweed system. Hydrobiologia 584:205-213

LaMontagne JL, Jackson LJ, Barclay RMR (2003) Compensatory growth responses of Potamogeton pectinatus to foraging by migrating trumpeter swans in spring stop over areas. Aquat Bot 76:235-244

Lauridsen TL, Jeppesen E, Østergard Andersen F (1993) Colonization of submerged macrophytes in shallow fish manipulated Lake Væng: impact of sediment composition and waterfowl grazing. Aquat Bot 46:1-15

Lehmann A, Jaquet J-M, Lachavanne J-B (1997) A GIS approach of aquatic plant spatial heterogeneity in relation to sediment and depth gradients, Lake Geneva, Switzerland. Aquat Bot 58:347361

Maron JL, Crone E (2006) Herbivory: effects on plant abundance, distribution and population growth. Proc R Soc B 273:25752584

Nolet BA (2004) Overcompensation and grazing optimisation in an aquatic system? Freshw Biol 49:1391-1399
Nolet BA, Drent RH (1998) Bewick's swans refuelling on pondweed tubers in the Dvina Bay (White Sea) during their spring migration: first come, first served. J Avian Biol 29:574-581

Nolet BA, Langevoord O, Bevan RM, Engelaar KR, Klaassen M, Mulder RJW, Van Dijk S (2001) Spatial variation in tuber depletion by swans explained by differences in net intake rates. Ecology 82:1655-1667

Nolet BA, Bevan RM, Klaassen M, Langevoord O, Vander Heijden YGJT (2002) Habitat switching by Bewick's swans: maximisation of average long-term energy gain? J Anim Ecol 71:979-993

Sandsten H (2002) Waterfowl herbivory on submerged macrophytes in lakes. $\mathrm{PhD}$ thesis. Lund University, Sweden

Santamaría L (2002) Selective waterfowl herbivory affects species composition in a submerged plant community. Arch Hydrobiol 153:353-365

Santamaría L, Rodríguez-Gironés MA (2002) Hiding from swans: optimal burial depth of sago pondweed tubers foraged by Bewick's swans. J Ecol 90:303-315

Scheffer M, Deredelikheid MR, Noppert F (1992) Distribution and dynamics of submerged vegetation in a chain of shallow eutrophic lakes. Aquat Bot 42:199-216

Van Donk E, Otte A (1996) Effects of grazing by fish and waterfowl on the biomass and species composition of submerged macrophytes. Hydrobiologia 340:285-290 